\section{TISSUE CULTURE}

Fuctors for Growth

from our Cell Biology Correspondent SERUM is the cocktail of life to most mammalian cells grown in tissue culture; without it they are unhappy, they cease to multiply and if deprived for more than two or three days they die. This requirement for serum is of course a great handicap, for it means that most cells cannot be grown in a defined and precisely reproducible medium; batches of serum vary and their composition is unknown. But there are two sides to every coin. If the factors in serum essential for survival and for the initiation of DNA synthesis and the cell cycle could be isolated pure, investigation of the way they act might throw considerable light on the questions posed by the existence of processes which regulate cell multiplication.

As the slow progress of the group at the Salk Institute centred round no lesser a biochemist than Holley testifies, the task of fractionating growth and survival factors from sera is proving to be far easier said than done. But after several years work the Salk group has now reached the point, as Paul, Lipton and Klinger report in the current issue of the Proceedings of the US National Academy of Sciences $(68,645 ; 1971)$, where they can isolate, partially pure, no less than three factors which control the initiation of DNA synthesis in 3T3 cells or 3T3 cells transformed by SV40 (SV3T3) and a fourth factor necessary for the survival of these cells in culture.

Apart from the straightforward tech. nical problems encountered when a complex mixture of molecules is fractionated, isolating growth and survival factors hinges on effective assays for these two properties. Paul et al. assayed growth factor activity by measuring ${ }^{3} \mathrm{H}$ thymidine uptake by cells maintained in a medium containing 0.4 or 0.2 per cent serum, enough to ensure survival of the cultures but no significant increase in the cell density. They measured survival factor activity by plating cells in a medium lacking any serum to which is added the fraction being assayed. A cell count 3-4 days later revealed if the fraction caused the cells to survive.

The growth promoting activity of whole rat serum proved to be stable over a wide $p \mathrm{H}$ range and, to cut a long story short, Paul et al. eventually developed a fractionation technique to exploit this fact. After a preliminary electrophoretic separation at $p \mathrm{H} 8.6$ on cellulose acetate, which partially separates a broad peak of activity which promotes DNA synthesis in 3T3 cells from a similar activity for SV3T3 cells, gel filtration on 'Sephadex G100' at pH 2.0 resolves three distinct peaks of . activity (peaks I, II, III). All three con- tain non-dialysable trypsin sensitive material which is presumably protein. Peaks I and III stimulate DNA synthesis by SV3T3 cells, 3T3 cells transformed by both polyoma virus and SV40 and the so-called flat revertants of SV3T3 cells isolated by Pollack (cells which grow like untransformed cells but retain the SV40 genome). These two factors, which in combination have an additive effect, seem therefore to be specific for cells carrying a tumour virus genome. By contrast the factor in peak II only stimulates DNA synthesis by untransformed 3T3 cells. But in spite of their ability to stimulate DNA synthesis, none of these factors can keep alive cells plated in media lacking all traces of complete serum. A fourth and distinct factor in complete serum, which on electrophoresis runs with the alpha globulins but is apparently distinct from them, seems to be essential for the survival of cells in culture.

Now that Paul and his colleagues have broken the back of the serum fractionation problem, more rapid progress towards the goal of complete purification and characterization of these four factors can now perhaps be anticipated. Furthermore, following Holley and Kiernan, Paul et al. have found in human urine factors similar to those in sera which seem to promote DNA synthesis.

This observation is of course important because it is far easier to collect urine than, for example, rat serum and it may therefore be possible to isolate larger quantities of these factors from this novel source. Then the problem will be discovering how the factors act. And it should be possible to test Balk's suggestion (Proc. US Nat. Acad. Sci., 68, 271 ; 1971) that the mitogenic factors in serum are released from precursors in plasma or from thrombocytes when blood is clotted during the preparation of serum.

\section{GREAT LAKES \\ Field Year Programmes}

from our Geomagnetism Correspondent

THE Great Lakes are a man-made disaster area by any standards and as a result a great deal of effort is being devoted to fundamental research in the area simply to find out what basic processes operate, how they are being affected by man and thus how the resulting eutrophication can be slowed

\title{
New Light on Regulation of Plant Senescence
}

Although the effects of light on the growth and early development of plants are well known, the influence of light on senescence in plants has been little studied. In the course of experiments designed to test the effect of treatment with low intensity white light on the grain yield in wheat, P. R. Walpole and D. G. Morgan of the University of Cambridge have uncovered a novel effect. It seems that if young wheat seedlings are exposed to an extended period of low intensity light, the senescence of the principal photosynthetic tissue is markedly accelerated.

Walpole and Morgan vernalized-in other words, promoted germination by chilling - wheat seeds for four weeks before growing the plants to the third leaf stage in a cool greenhouse. The plants were then transferred to a controlled environment chamber in which the daylength was set at $1 \mathrm{~h}$ and the light intensity was 2,850 foot candles at pot height. The plants were then transferred in groups of ten at weekly intervals to a second controlled environment cabinet in which the light intensity was only 700 foot candles at pot height. The groups were left in the low light conditions for one week before transfer back to the high light intensity environment.

This light regime delayed anthesis, that is the emergence of the anthers in the flower head, for two to three days, but only the light stress imposed when the plants were at an early stage in the development of the flower head markedly depressed the yield of grain from the ear. This reduction was due not to a reduction in the number of grains per ear, but to a decrease in the mean grain weight.

It seems likely therefore that this decrease in yield could be the consequence of some effect of the earlier low intensity light on the photosynthetic efficiency of the flag leaf area, the large area of green tissue above the flag leaf node which seems to take the major role in determining cereal yield. Walpole and Morgan, in fact, found that the low intensity light treatment accelerated yellowing of the photosynthetic tissue in this region, the loss of chlorophyll resulting in decreased photosynthetic efficiency.

Walpole and Morgan suggest that the low intensity light treatment may cause some subtle change in the balance of plant growth hormones which persists to modify the normal pattern of senescence. Equally these results could be interpreted as a discreet change in the way in which senescence may be coded in the genetic material. Whatever the mechanism, these studies have clearly opened a new approach to the problems of plant senescence. 